\title{
Permasalahan Implementasi Sistem Informasi Di Perguruan Tinggi Swasta
}

\author{
Mohamad Ali Murtadho ${ }^{1}$ dan Fathul Wahid ${ }^{2}$ \\ ${ }^{1}$ Sistem Informasi, Universitas Pesentren Tinggi Darul Ulum (Unipdu) Jombang \\ ${ }^{2}$ Teknik Informatika Fakultas Teknologi Industri Universitas Islam Indonesia (UII) Yogyakarta \\ E-mail: ${ }^{1}$ alimurtadho@ft.unipdu.ac.id, ${ }^{2}$ fathul.wahid@uii.ac.id
}

\begin{abstract}
Abstrak
Efektivitas implementasi sistem informasi dalam proses manajemen kelembagaan sering terhambat oleh banyak faktor. Sehingga mengakibatkan transformasi proses bisnis yang diharapkan dengan sistem informasi berakselerasi dengan cepat justru mengalami kemandekan. Penelitian ini mengkaji permasalahan dalam impelementasi sistem informasi di perguruan tinggi swasta. Penelitian ini dilakukan di salah satu perguruan tinggi swasta yang sedang berkembang di Jawa Timur berstatus universitas, ciri khas dari lembaga ini adalah perguruan tinggi Islam dan terletak di tengah-tengah komunitas pesantren. Metode penelitian yang digunakan pada penelitian ini adalah metode interpretif yaitu suatu upaya untuk mencari penjelasan peristiwa yang didasarkan perspektif dan pengalaman orang yang diteliti. Teknik pengumpulan data dilakukan dengan cara melakukan wawancara langsung dengan pendekatan semi terstruktur. Hasil wawancara di analisis menggunakan metode sensemaking. Dari hasil penelitian ini menunjukkan bahwa terdapat masalah yang sifatnya teknis dan non-teknis. Hasil temuan penelitian ini cenderung memperjelas atau menjabarkan teori penelitian sebelumnya.
\end{abstract}

Kata kunci: sistem informasi, sensmaking, masalah teknis, masalah non-teknis.

\begin{abstract}
The effectiveness of the implementation of information systems in the process of institutional management is often hampered by many factors. Resulting in business process transformation that is expected to accelerate quickly with information systems precisely to stagnate. In this research study the problems in the implementation of information systems in private universities. From the results of this studies indicates that there are problems that are both technical and non-technical. This study was conducted in one of the private universities that are developing in East Java university status, the hallmark of this institution is the Islamic universities and located in the middle of the pesantren community. The method used in this study is the interpretive method is an attempt to find an explanation of events that are based perspectives and experiences of people studied. Data collected by conducting interviews with semi -structured approach. Results of interviews in the analysis using method sensemaking. From the results of this study indicates that there are problems that are both technical and non - technical. These research findings tend to clarify or spell out the theory of previous research
\end{abstract}

Key word: information systems, sensmaking, technical issues, non-technical issues.

\section{Pendahuluan}

Sistem informasi digunakan oleh organisasi untuk membantu operasi organisasi menjadi lebih efisien sampai dengan perannya sebagai alat untuk memenangkan kompetisi. Selain untuk membantu operasi rutin perusahaan agar menjadi lebih efisien, sistem informasi juga merupakan faktor pembeda kompetitif yang utama, (O’Brien, 2006; Winarno, 2007). Sistem informasi dan teknologi informasi digunakan oleh organisasi untuk mengembangkan produk, jasa, dan kemampuan yang akan memberikan keunggulan dalam pasar persaingan. Namun dalam implementasi pemanfaatan sistem informasi tidaklah mudah dan belum tentu berjalan dengan baik, terjadi keluhan dan permasalahan di berbagai level pemangku kepentingan, padahal investasi sistem informasi yang dikeluarkan tidak sedikit.

Efektivitas implementasi sistem informasi dalam proses manajemen kelembagaan sering terhambat oleh banyak faktor. Sehingga mengakibatnya transformasi business process yang 
diharapkan dengan sistem informasi berakselerasi dengan cepat justru mengalami kemandekan. Oleh karena itu perlu dilakukan kajian terhadap masalah implementasi sistem informasi agar diperoleh penjelasan apa dan bagaimana implementasi sistem informasi di perguruan tinggi sehingga dapat diketahui permasalahan dan dicarikan solusinya.

Keberhasilan implementasi sistem dipengaruhi oleh berbagai faktor yang komplek. Sedangkan kegagalan implementasi sistem informasi, terjadi karena tidak kompatibelnya sistem dengan proses bisnis dan informasi yang diperlukan organisasi (Janson dan Subramanian 1996; Lucas et al. 1988 dikutip dari Budiyanto, 2009). Menurut Curry (2002), kegagalan implementasi sistem informasi dalam business process organisasi termasuk universitas (perguruan tinggi) bukan hanya akibat faktor teknis namun lebih kepada permasalahan non-teknis (faktor manusia, proses dan organisasi kerja). Berbeda dengan Curry, Mustakini (2007) membedakan kegagalan dalam implementasi sebuah sistem informasi menjadi dua aspek yaitu aspek teknis dan aspek non-teknis. Pertama adalah aspek teknis, yakni aspek yang menyangkut sistem itu sendiri yang merupakan kualitas dari teknis sistem informasi. Kualitas teknis yang buruk menyangkut masih banyaknya kesalahan-kesalahan sintak, kesalahan-kesalahan logik, dan bahkan kesalahan-kesalahan informasi. Sedangkan aspek yang kedua adalah aspek non-teknis yang berkaitan dengan persepsi pengguna sistem informasi yang menyebabkan pengguna mau atau enggan menggunakan sistem informasi yang telah dikembangkan.

Peneliti tertarik untuk melakukan kajian terhadap implementasi sistem informasi bermasalah di organisasi pendidikan atau perguruan tinggi swasta yang ditentukan berdasarkan persepsi dari pemakai atau pengguna dan orang-orang yang terlibat dalam implementasi sistem informasi di organisasi tersebut. Dengan demikian penelitian ini memiliki kelebihan, yaitu mencari penjelasan permasalahan dalam implementasi sistem informasi pada konteks perguruan tinggi swasta dari berbagai aspek yang ditentukan dari sudut pandang informan yang terlibat dalam implementasi sistem informasi tersebut sehingga data yang diperoleh lebih komprehensif.

Penelitian tersebut mempunyai manfaat sebagai "kisah dan rekam jejak" pengalaman dan catatan dalam implementasi sistem informasi dalam organisasi pendidikan tinggi swasta, sehingga dapat dijadikan sebagai pemebelajaran dalam penerapan sistem informasi dalam konteks perguruan tinggi swasta. Hal tersebut menjadi sangat penting dan sangat menarik untuk diteliti sehingga dapat menambah pengetahuan dan berkontribusi secara akademis dan praktis dalam implementasi sistem informasi bermasalah pada konteks perguruan tinggi khususnya perguruan tinggi swasta. Oleh karena itu penelitian ini difokuskan untuk memahami implementasi sistem informasi bermasalah pada konteks perguruan tinggi swasta.

\section{Metode Penelitian}

Metode penelitian yang digunakan pada penelitian ini adalah metode interpretif yaitu suatu upaya untuk mencari penjelasan peristiwa yang berdasarkan perspektif dan pengalaman orang yang diteliti. Metode ini sangat cocok dalam penelitian ini karena data yang digunakan berdasarkan perspektif dan pengalaman seseorang.

Penelitian ini dilakukan di salah satu perguruan tinggi swasta di Jawa Timur berstatus universitas yang sedang berkembang dengan jumlah mahasiswa sekitar 2500 mahasiswa dan sudah menerapkan sistem informasi dalam menjalankan proses kelembagaannya, ciri khas dari lembaga ini adalah perguruan tinggi Islam dan terletak di tengah-tengah komunitas pesantren.

Teknik pengumpulan data pada penelitian ini dilakukan dengan cara melakukan wawancara langsung. Wawancara dilakukan dengan pendekatan semi terstruktur yaitu dengan membuat panduan yang sifatnya terbuka yakni wawancara dengan jawaban terbuka atau tidak ada batasan, proses wawancara tersebut akan direkam dan ditranskrip kedalam bentuk tulisan, jika informan atau pihak yang diwawancarai tidak bersedia direkam maka akan dilakukan pencatatan. Isi pokok wawancara yang akan ditanyakan kepada masing-masinng sumber atau informan secara garis besar adalah sama, namun dalam pelaksanaannya tidak menutup kemungkinan terjadi improvisasi saat wawancara dan disesuaikan dengan wewenang dan kapasitas pihak yang diwawancarai.

Dari data hasil wawancara yang telah didapat, dianalisis menggunakan metode sensemaking. Menurut Spurgin, (2006:12) dalam Hidayat (2009) pendekatan sensemaking adalah seperangkat asumsi meta-teori yang mengarah secara eksplisit kepada sebuah pendekatan keseluruhan untuk 
menggunakan metodologi yang menyarankan metode yang tepat untuk membingkai (framing) pertanyaan, pengumpulan data, dan melakukan analisis untuk sampai kepada teori subtantif.

Menurut Langley (1999) dalam Wahid (2012), sensemaking ada beragam strategi: (1) narrative strategy; (2) quantification strategy; (3) alternate templates strategy; (4) grounded theory strategy; (5) visual mapping strategy; (6) temporal bracketing strategy; dan (7) synthetic strategy. Pada penelitian ini strategi yang digunakan adalah narrative strategy yaitu dengan menarasikan pendapat dari informan pada saat wawancara untuk mendapatkan 'jalinan cerita' antar dokumen (termasuk transkrip wawancara) kemudian ditarik keyword dari rangkaian kalimat yang menunjuk pada konsep tertentu.

\section{Hasil Penelitian dan Pembahasan}

Dari hasil wawancara dengan informan diketahui bahwa terdapat banyak permasalahan yang dihadapi dalam penerapan sistem informasi pada perguruan tinggi swasta baik yang bersifat teknis maupun non-teknis. Dalam penelitiannya, Mustakini (2007) membagi masalah sistem informasi menjadi dua aspek yaitu aspek teknis dan aspek non-teknis. Aspek teknis berkaitan dengan sistem itu sendiri yang merupakan kualitas dari teknis sistem informasi. Kualitas teknis yang buruk menyangkut masih banyaknya kesalahan-kesalahan sintak, kesalahan-kesalahan logik, dan bahkan kesalahan informasi. Sedangkan aspek yang kedua adalah aspek non-teknis yang berkaitan dengan persepsi pengguna sistem informasi yang menyebabkan pengguna menerima atau menolak menggunakan sistem informasi yang telah dikembangkan.

Dari hasil penelitian didapatkan dua kelompok permasalahan yang dihadapi dalam implementasi sistem informasi dan teknologi informasi di perguruan tinggi swasta yaitu teknis dan non-teknis. Adapun penjelasan temuan penelitian adalah sebagai berikut:

a. Permasalahan teknis yang ditemukan

Tabel 1 Masalah teknis implementasi Teknologi Informasi yang ditemukan

\begin{tabular}{|c|c|c|}
\hline $\mathrm{NO}$ & JENIS MASALAH & MASALAH \\
\hline \multirow[t]{4}{*}{1} & Internet & Kecepatan internet lambat \\
\hline & & Kapasitas bandwith rendah \\
\hline & & Internet kadang tidak dapat terkoneksi \\
\hline & & Rasio antara bandwith \& pengguna masih kurang \\
\hline \multirow[t]{5}{*}{2} & Infrastruktur & Kecepatan sistem jaringan lambat \\
\hline & Jaringan & Ketersediaan akses tidak merata \\
\hline & & Wireless Fidility (wifi) terkadang tidak aktif \\
\hline & & Jaringan komputer tidak terawat \\
\hline & & Sinyal wifi kurang bagus \\
\hline \multirow[t]{4}{*}{3} & Perangkat Komputer & Spesifikasi rendah dan tidak upgrade \\
\hline & Dan Pendukungnya & Komputer kurang perawatan \\
\hline & & Tidak sesuai kebutuhan \\
\hline & & Print sering rusak \& hasil kurang bagus \\
\hline \multirow[t]{2}{*}{4} & Keamanan Sistem & Keamanan sistem informasi dan web rendah \\
\hline & & Sistem informasi diadopsi dari sistem yang sudah jadi \\
\hline \multirow[t]{3}{*}{5} & Integrasi Sistem & Belum adanya integrasi antar sistem \\
\hline & & Masih ada unit kerja yang belum memiliki sistem \\
\hline & & Data dan informasi antar unit tidak singkron \\
\hline \multirow[t]{2}{*}{6} & Ketersediaan Sistem & Sistem informasi \& web terkadang tidak dapat diakses \\
\hline & & Server sering restart dan tidak aktif atau mati \\
\hline 7 & Pemeliharaan TI & Kurangnya pemeliharaan dan monitoring \\
\hline \multirow{2}{*}{8} & Masalah I ain & Letak gedung menyebar dan berjauhan \\
\hline & Masalah Lain & Tidak adanya perencanaan IT dengan pembangunan gedung \\
\hline
\end{tabular}

Mayoritas informan ketika ditanyakan bagaimana permasalahan yang dihadapi dalam penggunaan sistem informasi mengatakan bahwa permasalahan teknis yang dihadapi adalah masalah internet, infrastruktur jaringan, perangkat komputer dan pendukungnya, keamanan sistem, integrasi sistem, ketersediaan sistem, dan pemeliharaan Teknologi Informasi. Untuk lebih jelasnya bisa dilihat pada Tabel 1. Dari Tabel 1 dapat dikatakan bahwa temuan dalam penelitian ini memperjelas penelitian yang dilakukan Mustakini (2007) tentang masalah implementasi sistem informasi dalam aspek teknis 
dimana penelitian Mustakini menerjemahkan masalah teknis implementasi sistem informasi secara general dengan membatasi masalah teknis dengan batasan kualitas dari teknis sistem informasi.

\section{b. Jenis masalah non-teknis yang ditemukan}

Selain masalah aspek teknis yang telah dipaparkan di atas, peneliti juga banyak menemukan permasalahan yang berkaitan dengan aspek non-teknis implementasi sistem informasi dan teknologi informasi di perguruan tinggi swasta yang peneliti kelompokkan seperti Tabel 2.

Tabel 2 Masalah non-teknis implementasi Teknologi Informasi di Perguruan Tinggi Swasta

\begin{tabular}{|c|c|c|}
\hline $\mathrm{NO}$ & KELOMPOK MASALAH & POKOK MASALAH \\
\hline \multirow[t]{2}{*}{1} & Penerimaan dan partisipasi & Partisipasi Dalam menggunakan TI masih rendah \\
\hline & & Terjadi resistensi atau penolakan dari SDM \\
\hline \multirow[t]{3}{*}{2} & Budaya dan perilaku & Budaya kerja penggunaan TI masih rendah \\
\hline & & Belum mampu membudayakan kerja berbasis TI \\
\hline & & Pengguna enggan menggunakan sistem \\
\hline \multirow[t]{4}{*}{3} & Sumber daya manusia & Sumber daya manusia untuk TI masih terbatas \\
\hline & & $\begin{array}{l}\text { sebagian SDM masih ada yang belum mampu menggunakan Teknologi } \\
\text { informasi }\end{array}$ \\
\hline & & Dukungan dan komitmen sumberdaya manusia \\
\hline & & Kesiapan SDM dalam menggunakan Teknologi informasi \\
\hline \multirow[t]{2}{*}{4} & Perencanaan TI & Perencanaan teknologi informasi yang belum matang \\
\hline & & Pembangunan teknologi informasi bersifat temporal \\
\hline \multirow[t]{6}{*}{5} & Manajemen dan tatakelola TI & Tidak ada petugas yang memonitoring \\
\hline & & sosialisasi penggunaan sistem informasi yang rendah \\
\hline & & kebijakan penggunaan sistem informasi kurang sosialisasi \\
\hline & & sistem informasi belum mampu memangkas proses bisnis \\
\hline & & kurangnya pengembangan sistem informasi \\
\hline & & kurangnya pelatihan penggunaan sistem informasi \\
\hline \multirow[t]{6}{*}{6} & Organisasi & Sistem informasi tidak selaras dengan organisasi \\
\hline & & Sistem informasi tidak sesuai kebutuhan organisasi \\
\hline & & $\begin{array}{l}\text { Sistem informasi yang tidak singkron dan tidak terintegrasi dengan unit } \\
\text { kerja lainnya }\end{array}$ \\
\hline & & Kesiapan organisasi dalam menggunakan teknologi informasi \\
\hline & & Kesiapan organisasi dalam menggunakan teknologi informasi \\
\hline & & Organisasi belum mampu bersinergi dengan organisasi diluar \\
\hline \multirow[t]{2}{*}{7} & Konten sistem informasi & kompetensi sumberdaya rendah untuk mengisi konten \\
\hline & & konten yang tidak up to date \\
\hline \multirow[t]{4}{*}{8} & Anggaran dan biaya & Cost - benefit belum dapat diukur \\
\hline & & Anggaran TI yang masih rendah \\
\hline & & investasi TI belum menjadi skala prioritas \\
\hline & & Anggaran TI yang masih rendah \\
\hline \multirow[t]{5}{*}{9} & Dukungan Pimpinan Dan & Persepsi pimpinan terhadap manfaat TI \\
\hline & Karakter Kepemimpinan & Dukungan pimpinan masih rendah \\
\hline & & Komitmen Pimpinan \\
\hline & & Pimpinan belum mampu memanfaatkan TI untuk tujuan strategi \\
\hline & & Karakter kepemimpinan \\
\hline
\end{tabular}

Dari Tabel 2 dapat diketahui bahwa ada sembilan kelompok masalah non-teknis dalam implementasis sistem informasi di perguruan tinggi swasta, yaitu 1. Penerimaan dan partisipasi, 2). Budaya dan perilaku, 3). Sumber daya manusia 4), perencanaan TI, 5). Manajemen dan tatakelola TI, 6). Organisasi 7). Konten sistem informasi, 8). Anggaran dan biaya, 9). Dukungan pimpinan dan kerakter kepemimpinan. Beragam masalah non-teknis yang diungkapan informan terkait implementasi sistem informasi di perguruan tinggi swasta dengan statement yang berbeda-beda sesuai dengan apa yang diketahui dan dialami oleh informan. 


\section{Kesimpulan}

Penelitian ini cenderung memperjelas atau menjabarkan penelitian sebelumnya, dimana dalam impelementasi sistem informasi khususnya di perguruan tinggi swasta terdapat permasalahan yang sifatnya teknis dan non-teknis. Masalah teknis, diantaranya adalah a). internet, b). infrastruktur jaringan, c). perangkat komputer dan pendukungnya, d). keamanan sistem, e). integrasi sistem, f). ketersediaan sistem, dan g). pemeliharaan TI. Sedangkan masalah non-teknis dalam implementasis sistem informasi di perguruan tinggi swasta, yaitu a). Penerimaan dan partisipasi, b). Budaya dan perilaku, c). Sumber daya manusia, d), perencanaan, e). Manajemen dan tatakelola TI, f). Organisasi g). Konten sistem informasi, h). Anggaran dan biaya, i). Dukungan pimpinan dan karakter kepemimpinan

\section{Referensi}

Budiyanto. (2009). Tesis: Evaluasi Kesuksesan Sistem Informasi Dengan Pendekatan Model Delone Dan Mclean (Studi Kasus Implementasi Billing SystemDi RSUD Kabupaten Sragen). Surakarta: Magister Akutansi FE Universitas Sebelas Maret.

Curry, J. R. (2002). The Organizational Challege: IT and Revolution in Higher . Educause Review, Maret-April, 40-48.

Hidayat, M. R. (2009). Pencarian Dan Pemaknaan Metodologi. Jakarta: FIB UI.

Janson, M. A., dan Subramanian, A. (1996). Packaged software: Selection and Implementation Policies. INFOR 34(2), 133-151.

Mustakini, J.H. (2007). Sistem Informasi Keperilakuan. Yogyakarta: Andi.

O'Brien, J. A. (2006). Pengantar Sistem Informasi Perspektif Bisnis dan Manajerial Edisi 12. Jakarta: Salemba.

Wahid, F. (2004). Peluang Dan Tantangan Pemanfaatan Teknologi Informasi Di Perguruan Tinggi. Media Informatika, 2, 11-22.

Winarno, W. W. (2007). Sistem Informasi Manajemen. Yogyakarta: STIE YKPN. 